\title{
Compostos fenólicos e capacidade antioxidante de cultivares de uvas Vitis labrusca $\mathbf{L}$. e Vitis vinifera $L$. \\ Phenolic compounds and antioxidant activity of \\ Vitis labrusca and Vitis vinifera cultivars
}

\author{
Lucile Tiemi $\mathrm{ABE}^{1}$, Renata Vieira DA MOTA ${ }^{2}$, Franco Maria LAJOLO ${ }^{1}$, Maria Inés GENOVESE ${ }^{1 *}$
}

\begin{abstract}
Resumo
O conteúdo de compostos fenólicos, incluindo resveratrol, antocianinas e outros flavonóides, e a capacidade antioxidante de cinco cultivares de uvas produzidas em Minas Gerais foram determinados. O conteúdo de fenólicos totais, determinado através do método de Folin-Ciocalteau variou significativamente, entre $65 \pm 1$ e $390 \pm 30 \mathrm{mg}$ equivalentes de ácido gálico.100 g ${ }^{-1}$ de amostra base úmida (b.u.). O conteúdo de antocianinas totais quantificado por CLAE variou entre 6,7 $\pm 0,2$ e $154 \pm 4 \mathrm{mg}$ equivalentes de cianidina.100 g ${ }^{-1}$ (b.u.). Outros flavonóides encontrados foram catequina, epicatequina, quercetina, caempferol além dos ácidos hidroxicinâmicos. O resveratrol foi encontrado em três cultivares, variando entre $0,022 \pm 0,001$ e $0,60 \pm 0,03 \mathrm{mg} .100 \mathrm{~g}^{-1}$ (b.u.). A capacidade antioxidante foi analisada usando o método de seqüestro de radicais livres do DPPH (2,2-difenil-1-picrilhidrazila), que variou entre $2,7 \pm 0,1$ e $19 \pm 2 \mu$ moles equivalentes de Trolox.g ${ }^{-1}$ de amostra (b.u.), mostrando boa correlação com o conteúdo de fenólicos totais. As uvas tintas de coloração mais escura apresentaram maior conteúdo de antocianinas, e conseqüentemente maior teor de fenólicos totais e capacidade antioxidante.

Palavras-chave: flavonóides; capacidade antioxidante; Vitis sp.
\end{abstract}

\begin{abstract}
Phenolic compounds including resveratrol, anthocyanins and other flavonoids and antioxidant capacity were evaluated for five grape cultivars cultivated in Minas Gerais (Brazil). The content of total phenolic determined by the Folin Ciocalteau method varied significantly, from $65 \pm$ 1 to $390 \pm 30 \mathrm{mg}$ gallic acid equivalents. $100 \mathrm{~g}^{-1}$ of FW (Fresh Weight). The content of total anthocyanins quantified by HPLC varied from $6.7 \pm 0.2$ to $154 \pm 4 \mathrm{mg}$ of cyanidin equivalents. $100 \mathrm{~g}^{-1} \mathrm{FW}$. Resveratrol was found in three cultivars, in contents from $0.022 \pm 0.001$ to $0.60 \pm 0.03 \mathrm{mg} .100 \mathrm{~g}^{-1}$ of FW. In addition to hydroxicynnamic acids, other flavonoids such as catechin, epicatechin, quercetin and kaempferol were also present. The antioxidant capacity was analyzed using the DPPH (2,2-diphenyl-1-picrylhydrazyl) radical scavenging method and varied from $2.7 \pm 0.1$ to $19 \pm 2 \mu \mathrm{mol}$ trolox equivalents. ${ }^{-1} \mathrm{FW}$, showing good correlation with the content of total phenolics. The darker red grapes presented higher anthocyanin contents and consequently higher total phenolic contents and antioxidant capacity.

Keywords: flavonoids; antioxidant capacity; Vitis sp.
\end{abstract}

\section{Introdução}

Vários efeitos benéficos à saúde têm sido atribuídos aos compostos fenólicos presentes nas frutas, vegetais, chás e vinhos. Estudos epidemiológicos, clínicos e in vitro mostram múltiplos efeitos biológicos relacionados aos compostos fenólicos da dieta, tais como: atividades antioxidante, antiinflamatória, antimicrobiana e anticarcinogênica ${ }^{14,9,6,3}$.

As uvas são consideradas uma das maiores fontes de compostos fenólicos quando comparadas a outras frutas e vegetais ${ }^{24}$, porém a grande diversidade entre as cultivares resulta em uvas com diferentes características, tanto de sabor quanto de coloração, o que certamente está associado com o conteúdo e o perfil dos polifenólicos. Por ser a matéria-prima para a produção de vinhos e sucos, é importante conhecer os teores de compostos fenólicos das uvas, pois estes podem influenciar a qualidade dos produtos finais.

Os compostos fenólicos das uvas podem ser classificados em flavonóides e não-flavonóides. Do primeiro grupo fazem

Recebido para publicação em 13/9/2006

Aceito para publicação em 23/4/2007 (001847)

Departamento de Alimentos e Nutrição Experimental,

Faculdade de Ciências Farmacêuticas, Universidade de São Paulo - USP,

Av. Prof. Lineu Prestes, 580, Bloco 14, CEP 05508-900, São Paulo - SP, Brasil

E-mail: genovese@usp.br

2 Estação Experimental de Caldas, EPAMIG,

Av. Santa Cruz, 500, CP 33, CEP 37780-000, Caldas - MG, Brasil

${ }^{*}$ A quem a correspondência deve ser enviada parte os flavanóis (catequina, epicatequina e epigalocatequina), flavonóis (caempferol, quercetina e miricetina) e antocianinas, e ao segundo grupo pertencem os ácidos fenólicos, hidroxibenzóicos e hidroxicinâmicos ${ }^{5}$. Além destes compostos, pode-se encontrar também o resveratrol, polifenol pertencente à classe dos estilbenos. As antocianinas são flavonóides amplamente distribuídos na natureza e são responsáveis pela maioria das cores azul, violeta e todas as tonalidades de vermelho, presentes em flores e frutos. Em uvas tintas, as antocianinas constituem a maior porcentagem de compostos fenólicos, representando um constituinte importante para a produção de vinhos tintos porque contribuem para os atributos sensoriais e, principalmente, para a coloração do vinho ${ }^{28}$. As catequinas e epicatequinas, presentes principalmente em sementes de uvas, são os principais compostos fenólicos responsáveis pelo sabor e adstringência de vinhos e sucos de uva. Quercetina, caempferol e miricetina, embora presentes em menor quantidade, possuem importante papel no desenvolvimento da coloração do vinho, atuando como co-pigmentos junto às antocianinas. Os ácidos fenólicos, também usualmente encontrados em baixas concentrações, representam um dos principais compostos em uvas brancas, influenciando o aroma e gosto dos vinhos. Além das características organolépticas, todos esses compostos contribuem para aumentar as propriedades benéficas dessas bebidas. Dentre todos os compostos fenólicos das uvas, o resveratrol tem atraído atenção especial nas últimas décadas em decorrência de estudos epidemiológicos que mostram correlação inversa 
entre o consumo moderado de vinho e a incidência de doenças cardiovasculares. Os estudos com resveratrol tiveram início a partir de investigações relacionadas à dieta francesa, que apesar de rica em gorduras de origem animal, parece associada à baixa incidência de doenças cardiovasculares, fenômeno conhecido como "Paradoxo Francês"22. O resveratrol pode ser encontrado em amendoim, cacau, algumas variedades de chás, porém, a principal fonte são as uvas e seus derivados ${ }^{5,8}$. Sua biossíntese nas plantas é induzida por fatores ambientais como a radiação UV e infecção por fungos ${ }^{22}$.

Considerando-se a grande variedade de compostos bioativos das uvas, o presente trabalho teve como objetivos: identificar e quantificar os compostos fenólicos, incluindo resveratrol, antocianinas e outros flavonóides em cinco cultivares de uvas, entre americanas e viníferas, cultivadas em Minas Gerais, e avaliar sua capacidade antioxidante.

\section{Material e métodos}

\subsection{Material}

\section{Amostras}

Foram amostrados cachos das variedades Vitis labrusca e Vitis vinifera cultivados em Minas Gerais na safra 2005/2006. Foram analisadas duas cultivares de Vitis labrusca (Niágara rosada nos porta-enxertos IAC 766 e 196-17, e Folha de figo nos porta-enxertos 420A e 196-17) e três cultivares de Vitis vinifera (Syrah - porta-enxerto $3309 \mathrm{C}$, Merlot - porta-enxerto 1103 P e Moscato Embrapa - porta-enxerto IAC 766). Todas as amostras foram trituradas sob nitrogênio líquido, liofilizadas e armazenadas a $-80{ }^{\circ} \mathrm{C}$ até o momento da análise.

\subsection{Métodos de análise}

\section{Análises físico-químicas do mosto}

O acompanhamento da maturação e a determinação do ponto de colheita foram realizados através da amostragem de 200 bagas ao acaso no vinhedo. A maturação foi acompanhada por avaliação semanal do teor de sólidos solúveis totais, $\mathrm{pH}$ e acidez total titulável, e o ponto de colheita estabelecido quando a concentração de açúcares e a acidez titulável mantiveram-se estáveis após avaliações consecutivas. Na colheita, as bagas foram esmagadas manualmente, e o mosto extraído utilizado para as análises físico-químicas de $\mathrm{pH}$ (pHmetro calibrado com os padrões pH 4 e 7), sólidos solúveis totais ( ${ }^{\circ} \mathrm{Brix}$ ) em refratômetro portátil e acidez total titulável por titulação com $\mathrm{NaOH}$ 0,1 N e fenolftaleína como indicador ${ }^{18}$.

\section{Fenólicos totais}

O conteúdo de fenólicos totais dos extratos metanólicos foi determinado de acordo com o método de ZIELINSKI e KOZLOWSKA $^{40}$, em espectrofotômetro modelo Ultrospec 2000 (Amersham Biosciences, Cambridge, Reino Unido), utilizandose reagente de Folin-Ciocalteau e ácido gálico como padrão. Os resultados obtidos foram expressos como equivalentes de ácido gálico. $100 \mathrm{~g}^{-1}$ amostra base úmida (b.u.).

\section{Quantificação de flavonóides e resveratrol}

\section{Extração}

Amostras previamente pulverizadas ( $1 \mathrm{~g}$ ) foram extraídas em Ultra-Turrax (Polytron ${ }^{\circledR}$-Kinematica GnbH, Kriens-Luzern, Suíça) com metanol:água:ácido acético $\left(70: 30: 5{\left.\mathrm{v} . \mathrm{v}^{-1}\right)}^{-1}\right.$ por $1 \mathrm{mi}-$ nuto em velocidade 5 , em banho de gelo. Os extratos obtidos foram filtrados utilizando-se papel de filtro Whatman n. 6. O resíduo foi re-extraído mais duas vezes e o extrato obtido foi concentrado utilizando-se Rotaevaporador (RE 120 - Büchi, Flawil, Suíça), em temperatura de banho a $40{ }^{\circ} \mathrm{C}$, até o volume de aproximadamente $20 \mathrm{~mL}$, e então ajustado com água para balão volumétrico de $25 \mathrm{~mL}^{2}$.

\section{Extração em fase sólida}

Alíquota do extrato obtido anteriormente foi passada através da coluna ( $1 \mathrm{~g}$ ) de poliamida SC 6 (Macherey-Nagel Gmbh and Co., Duren, Alemanha) previamente condicionada com $20 \mathrm{~mL}$ de metanol e $60 \mathrm{~mL}$ de água. A coluna foi lavada com $20 \mathrm{~mL}$ de água e a eluição feita primeiro com $40 \mathrm{~mL}$ de metanol e posteriormente com $40 \mathrm{~mL}$ de metanol:amônia $\left(99,5: 0,5 \mathrm{v} \cdot \mathrm{v}^{-1}\right)^{2}$.

\section{Hidrólise ácida de glicosídeos para identificação das antocianidinas}

Foi realizada hidrólise ácida segundo ORDAZGALINDO et al. ${ }^{29}$. Uma alíquota do extrato aquoso obtido após rotaevaporação foi passada em coluna de poliamida, como descrito anteriormente e eluída com $\mathrm{MeOH} / \mathrm{HCl}$ 0,01\%. $\mathrm{O}$ extrato foi rotaevaporado até secura e posteriormente tratado com $10 \mathrm{~mL}$ de $\mathrm{HCl} 2 \mathrm{~N}$ durante uma hora em banho-maria fervente, sob refluxo de nitrogênio.

\section{Análise por CLAE}

A identificação e quantificação dos flavonóides e resveratrol foram realizadas utilizando-se coluna Prodigy $5 \mu$ ODS(3) 250 x 4,60 mm (Phenomenex Ltd, Reino Unido). Utilizou-se gradiente de solventes constituído por A. Água : Tetrahidrofurano : Ácido trifluoroacético $98: 2$ : 0,1 e B. Acetonitrila, na proporção de $17 \%$ de B por 2 minutos aumentando para 25\% B após 5 minutos, 35\% B após mais 8 minutos e 50\% B após mais 5 minutos. Para limpeza da coluna, a \% de B foi aumentada então para 90 e a seguir re-equilibrada nas condições iniciais por 10 minutos. Foi utilizado o cromatógrafo líquido da Hewlett Packard série 1100, equipado com detetor com arranjo de diodos (DAD). A identificação foi feita a partir da comparação dos tempos de retenção e dos espectros com os dos espectros padrões, armazenados na Biblioteca da ChemStation. Os padrões de antocianinas foram adquiridos da Extrasynthese (Genay, França) e os dos outros flavonóides e do resveratrol da Sigma Chemical Co. (St. Louis, E.U.A.). As amostras foram injetadas em duplicata e os resultados expressos em miligramas equivalentes de aglicona por $100 \mathrm{~g}$ de amostra base úmida ${ }^{2}$. 


\section{Capacidade antioxidante}

A capacidade antioxidante foi avaliada utilizando-se o método do seqüestro de radicais livres do DPPH (2,2-difenil1-picrilhidrazila) em microplaca ${ }^{10}$. Uma alíquota de $250 \mu \mathrm{L}$ da solução metanólica de DPPH $20 \mathrm{mg} \cdot \mathrm{L}^{-1}$ foi adicionada a $50 \mu \mathrm{L}$ do extrato metanólico. Após 20 minutos em ausência de luz, realizaram-se as leituras de absorbância a $517 \mathrm{~nm}$ em espectrofotômetro para microplaca Benckmark Plus (BioRad, California, E.U.A.). Como controle utilizou-se solução de Trolox, e foram preparados os brancos correspondentes ao ensaio DPPH, aos padrões e às amostras. Os cálculos foram efetuados com o auxílio da seguinte fórmula:

$\%$ descoloração do DPPH =

$\left[\frac{1-(\text { A amostra }- \text { A branco da amostra }) \times 100}{\text { A branco do ensaio DPPH }}\right]$

em que: A amostra = absorbância da amostra a 517 nm; A branco da amostra = absorbância do branco da amostra a 517 nm; A branco do ensaio DPPH = absorbância do branco do ensaio DPPH a $517 \mathrm{~nm}$.

\section{Determinação de antocianinas totais}

As antocianinas totais foram quantificadas de acordo com o método descrito por WROLSTAD ${ }^{38}$, com modificações. Para as medidas de absorbância foi utilizado o espectrofotômetro modelo Ultrospec 2000 (Amersham Biosciences, Cambridge, Reino Unido). A amostra liofilizada $(0,2 \mathrm{~g})$ foi triturada em UltraTurrax (Polytron ${ }^{\circledast}$-Kinematica GnbH, Kriens-Luzern, Suíça) com $20 \mathrm{~mL}$ de metanol: ácido clorídrico $\left(99,9: 0,1 \mathrm{v} \cdot \mathrm{v}^{-1}\right)$ e centrifugada a 2000 g por 15 minutos $\left(4^{\circ} \mathrm{C}\right.$ ). Uma alíquota do sobrenadante foi diluída com tampão cloreto de potássio 0,025 M, pH 1,0, em proporções variando entre 5 e 25 vezes, de acordo com a coloração da amostra. A leitura da absorbância foi realizada a $510 \mathrm{~nm}$, considerando a absorbância máxima para cianidina3-glicosídeo, e a $700 \mathrm{~nm}$ para descontar a turbidez da amostra. Outra alíquota da amostra foi diluída com a mesma proporção em solução tampão acetato de sódio $0,4 \mathrm{M}, \mathrm{pH} 4,5$, e as leituras realizadas nos mesmos comprimentos de onda. A absorbância foi então calculada, usando-se a seguinte fórmula:

$\mathrm{A}=\left(\mathrm{A}_{510 \mathrm{~nm}}-\mathrm{A}_{700 \mathrm{~nm}}\right)_{\mathrm{pH}=1,0}-\left(\mathrm{A}_{510 \mathrm{~nm}}-\mathrm{A}_{700 \mathrm{~nm}}\right)_{\mathrm{pH}=4,5}$

O conteúdo de antocianinas (mg. $100 \mathrm{~g}^{-1}$ ) foi calculado como cianidina-3-glicosídeo ( $\mathrm{PM}=449,2)$ através da fórmula:

$\mathrm{C}_{\left(\mathrm{mg} .100 \mathrm{~g}^{-1}\right)}=\frac{\mathrm{A} \times \mathrm{PM} \times \text { fator de diluição }}{\varepsilon \times 1}$ em que $\varepsilon=$ absortividade molar $\left(26900\right.$ mol.L $\left.{ }^{-1}\right)$ e $1=$ espessura da cubeta $(\mathrm{cm})$.

\section{Análise estatística dos resultados}

Os resultados foram expressos na forma de média \pm desvio-padrão $(\mathrm{n}=3$ ). Para a análise estatística dos resultados utilizou-se o programa Statistica versão 5.0 da StatSoft (Tulsa, E.U.A.). A comparação das médias foi realizada através de análise de variância (ANOVA) e a seguir pelo teste LSD ( $p<0,05)$.

\section{Resultados e discussão}

A fase de maturação das bagas abrange o período que vai da mudança de cor até a colheita. Pode durar de 30 a 70 dias, dependendo da cultivar, do porta-enxerto e da região de cultivo. É nesta fase que ocorrem as mudanças nos teores de açúcares, acidez, compostos fenólicos, amolecimento e síntese de cor e aroma, que definirão a qualidade da uva ${ }^{30}$. O acúmulo de açúcar é o fenômeno mais importante da maturação, não somente pela quantidade de álcool que dele deriva, mas também por servir de origem a outros compostos como os polifenóis, as antocianinas ou outros compostos relacionados ao aroma.

A acidez titulável decresce ao longo da maturação. Entre os fatores que determinam a redução da acidez do mosto, destacam-se: a diluição dos ácidos devido ao aumento do volume da baga, sua utilização no processo respiratório e a migração de bases, que neutralizam os ácidos e que produzem um aumento do $\mathrm{pH}$ e uma redução na acidez total ${ }^{7}$.

A Tabela 1 ilustra a composição físico-química do mosto das diferentes cultivares no ponto de colheita. Pode-se notar que as cultivares viníferas apresentaram maior potencial de produção de açúcar e maior acidez residual do que as cultivares americanas.

Observa-se diferença no teor de acidez total titulável nas cultivares Niágara Rosada (porta-enxertos IAC 766 e 196-17) e Folha de Figo (porta-enxertos 420A e 196-17) e no teor de sólidos solúveis totais da cultivar Folha de Figo (porta-enxertos 420A e 196-17). Esta diferença pode ser atribuída à influência do porta-enxerto, pois as bagas foram colhidas de videiras cultivadas em um único talhão e manejadas sob o mesmo sistema de condução, portanto submetidas às mesmas condições de solo, luminosidade e temperatura. Diversos trabalhos têm demonstrado diferenças no comportamento da copa quanto ao pegamento de enxertia, vigor, e à qualidade da uva e do mosto em função do porta-enxerto utilizado ${ }^{1,13,32}$. ALVARENGA et al. ${ }^{1}$ observaram que videiras da cultivar Niágara Rosada apresentaram maturação antecipada quando enxertadas sobre os porta-enxertos Gravesac e 420A, enquanto que nas plantas enxertadas sobre IAC 313 e IAC 572 a maturação foi retardada.

Tabela 1. Características analíticas do mosto de cultivares de Vitis labrusca e Vitis vinifera cultivadas em Minas Gerais na safra 2005/2006.

\begin{tabular}{lcccccc}
\hline \multicolumn{1}{c}{ Variável } & $\begin{array}{c}\text { Niágara rosada } \\
\text { IAC 766 }\end{array}$ & $\begin{array}{c}\text { Niágara rosada } \\
196-17\end{array}$ & $\begin{array}{c}\text { Folha de figo } \\
420 \mathrm{~A}\end{array}$ & $\begin{array}{c}\text { Folha de figo } \\
196-17\end{array}$ & Syrah & Merlot \\
\hline${ }^{\circ}$ Brix & 15,3 & 15,5 & 15,6 & 12,9 & 17,5 & 21,2 \\
Acidez titulável (meq.L ${ }^{-1}$ ) & 94,6 & 73,8 & 65,2 & 73,5 & 106,0 & 108,0 \\
pH & 3,26 & 3,27 & 3,19 & 3,18 & 3,43 & 3,33 \\
\hline
\end{tabular}

Resultados expressos como média $\left(\mathrm{n}=3\right.$ ). Os coeficientes de variação foram menores que $5 \%$ ( ${ }^{\circ} \mathrm{Brix}$, Acidez titulável) e $1 \%(\mathrm{pH})$. 
GONÇALVES et al. ${ }^{13}$ observaram menor teor de sólidos solúveis quando a cultivar Folha de Figo foi enxertada sobre os portaenxertos Jacquez e IAC 313.

A Tabela 2 mostra a composição de compostos fenólicos das diferentes cultivares de uvas. As antocianinas foram os compostos encontrados em maior porcentagem nas cultivares Folha de figo, nos porta-enxertos 420A e 196-17, Syrah e Merlot (Tabela 2). As principais antocianinas presentes em uvas são a cianidina, peonidina, delfinidina, petunidina e malvidina ${ }^{28,19,31}$. Dentre as cultivares de uvas avaliadas, as antocianinas identificadas foram a malvidina, delfinidina, peonidina e cianidina em diferentes proporções. Na cultivar Folha de Figo, a proporção das antocianinas identificadas foi de 5:4:1 para malvidina: delfinidina: peonidina. Em uvas da cultivar Syrah e Merlot a proporção foi respectivamente de 4,5:3:2,5 e 4:3:3 para malvidina: peonidina: delfinidina. POMAR, NOVO e MASA ${ }^{31}$ observaram que a malvidina foi a antocianina encontrada em maior proporção ao avaliarem 50 variedades de Vitis vinifera. Da mesma forma, em outro estudo de cultivares de Vitis vinifera, a malvidina representou cerca de $67 \%$ do total de antocianinas, seguida pela peonidina, petunidina e delfinidina, sendo a cianidina a menos abundante ${ }^{19}$. A predominância da malvidina provavelmente é uma característica comum no perfil das antocianinas em Vitis vinifera. As uvas da cultivar Niágara rosada apresentaram um perfil bastante diferenciado em relação a outras uvas. A única antocianina detectada nestas uvas foi a cianidina, a qual não foi encontrada em nenhuma outra cultivar. A composição das antocianinas na uva depende primeiramente de fatores genéticos, porém a distribuição destes compostos durante a maturação da uva é ainda influenciada pelas condições climáticas e pelas características físico-químicas do solo ${ }^{31}$. Nas cultivares de uvas analisadas, o conteúdo de antocianinas totais, determinado pelo método do $\mathrm{pH}$ diferencial,

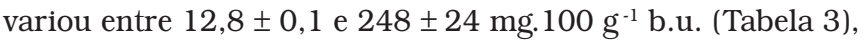
sendo significativamente maior nas uvas tintas de coloração mais escura em comparação com as uvas rosadas. A variação no teor de antocianinas totais em uvas foi também observada por KALLITHRAKA et al. ${ }^{19}$. Seus valores em diferentes variedades de Vitis vinifera variaram entre 8 e $191 \mathrm{mg} 100 \mathrm{~g}^{-1} \mathrm{~b} . \mathrm{u}$. O teor de antocianinas apresentou forte correlação com a capacidade antioxidante $(r=0,93)$, enquanto que a baixa correlação entre fenólicos totais e antocianinas $(r=0,65)$ representou a presença de outros compostos fenólicos, como as catequinas, epicatequinas, quercetinas, caempferol e ácidos hidroxicinâmicos, encontrados nas uvas. As antocianinas apresentam capacidade antioxidante superior a outros fenólicos presentes nas uvas, já que a correlação entre antocianinas e capacidade antioxidante foi superior à correlação entre fenólicos totais $\mathrm{e}$ capacidade antioxidante $(r=0,81)$.

HASSIMOTO, GENOVESE e LAJOLO ${ }^{15}$, avaliando a capacidade antioxidante de frutas, vegetais e polpas de frutas, observaram maior capacidade antioxidante em amostras contendo antocianinas, tanto pelo método do $\beta$-caroteno quanto pelo do lipossomo. A mesma relação foi demonstrada por MUNÕZ-ESPADA et al. ${ }^{28}$, avaliando as cultivares de Vitis vinifera e Vitis labrusca, nas quais se observou uma associação positiva entre o conteúdo de antocianinas e a capacidade antioxidante pelo método de seqüestro de radicais livres do DPPH. Por outro lado, KALLITHRAKA et al. ${ }^{19}$ encontraram correlação estatisticamente insignificante avaliando antocianinas totais e capacidade antioxidante em cultivares de Vitis vinifera, neste caso, ressaltando a importância de outros constituintes da uva. Catequinas e epicatequinas, por exemplo, têm demonstrado alta capacidade antioxidante e inibição da proliferação celular ${ }^{12,26}$. Há ainda evidências de que a ingestão de flavonóides como a quercetina e a catequina está associada à redução da oxidação do LDL e à redução da agregação plaquetária, contribuindo para a diminuição da progressão da lesão aterosclerótica ${ }^{16}$. O conteúdo de flavanóis (catequina e epicatequina), no presente estudo, variou entre 3,8 $\pm 0,1$ e $61 \pm 2 \mathrm{mg} .100 \mathrm{~g}^{-1}$. Estes com-

Tabela 2. Conteúdo de flavonóides, ácidos fenólicos e resveratrol expressos como agliconas (mg. $100 \mathrm{~g}^{-1}$ base úmida) de diferentes cultivares de videiras produzidas em Minas Gerais na safra 2005/2006.

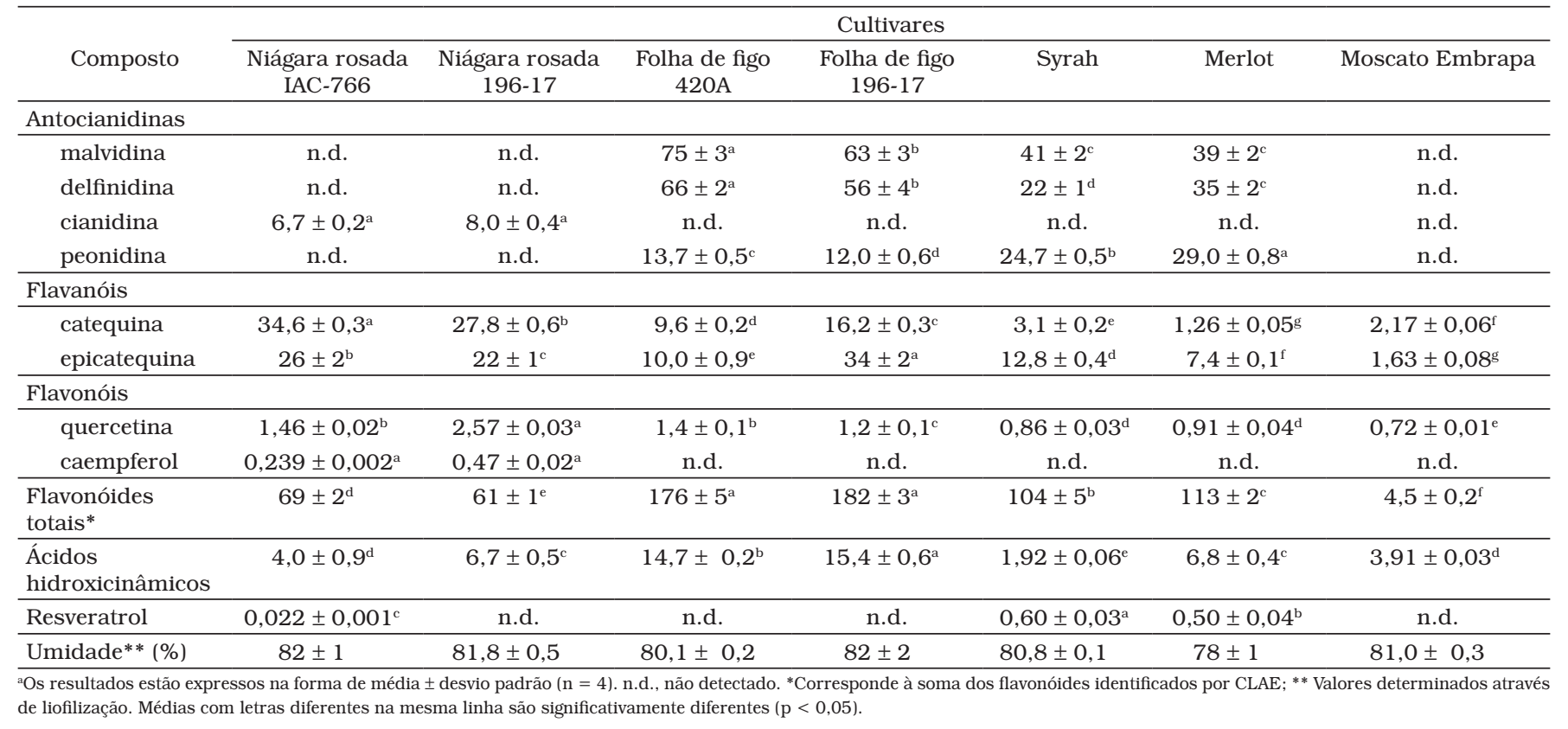


postos provavelmente são constituintes de sementes e cascas, segundo comparação realizada por MEYER et al. ${ }^{25}$ em relação ao conteúdo de flavanóis. Em uvas da variedade Cabernet Sauvignon não se detectou flavanóis nas bagas analisadas após a remoção das sementes, enquanto as bagas analisadas com as sementes apresentaram cerca de $33 \mathrm{mg} .100 \mathrm{~g}^{-1}$ de flavanóis. Já na variedade Petite Sirah, os valores observados foram 1,47 e 23,3 mg. $100 \mathrm{~g}^{-1}$, respectivamente, para uvas sem e com as sementes ${ }^{25}$. YILMAZ and TOLEDO ${ }^{39}$ encontraram proporções entre 6 e 9 vezes maiores de flavanóis nas sementes, em relação às cascas de uvas Vitis vinifera, variedades Merlot e Chardonnay. Em vinhos tintos, o conteúdo de flavanóis variou entre 189 e 265 mg equivalentes de catequina.L $L^{-1}{ }^{3}$. Observa-se dessa forma que os flavanóis presentes em sementes e cascas são extraídos durante o processo de vinificação, contribuindo para a composição de substâncias bioativas em vinhos.

O resveratrol foi encontrado em apenas três cultivares, representando a menor concentração dentre todos os outros fenólicos quantificados. A maioria dos estudos com resveratrol se refere a vinhos e sucos de uva, pois estes estudos tiveram início com bases epidemiológicas referentes ao consumo de vinhos. No presente estudo o conteúdo de resveratrol encontrado variou entre 0,022 e 0,60 $\mathrm{mg} 100 \mathrm{~g}^{-1}$ base úmida (b.u.). RIMANDO et al. ${ }^{33}$ encontraram valores de resveratrol entre 7 e 5800 ng.g $^{-1}$ base seca (b.s.), em espécies de Vitis, o que corresponderia a quantidades de no máximo $0,15 \mathrm{mg} .100 \mathrm{~g}^{-1}$ b.u., considerando valor de umidade em torno de $80 \%$. Outro estudo salienta a presença de resveratrol na casca, local onde é sintetizado e onde se concentra a maior quantidade da substância. Os valores relatados em cascas de uvas brancas e tintas, de Vitis vinifera variaram entre 1,1 e $12,3 \mathrm{mg} .100 \mathrm{~g}^{-1}$ b.s., sendo maiores nas cascas de uvas tintas. Em vinhos, os valores encontrados variaram desde 0,1 até 5,65 mg.L.1 21,11,37. Em sucos de uva produzidos no Brasil foram encontrados valores entre 0,19 e 0,90 mg de resveratrol. $\mathrm{L}^{-1}{ }^{35}$, quantidades inferiores às relatadas por ROMERO-PÉREZ et al. ${ }^{34}$ para sucos de uvas da Espanha, com teores entre 0,7 e 14,5 mg.L. A concentração de resveratrol em vinho e suco depende de diversos fatores, além da concentração inicial da substância na uva. Baseando-se no fato de que o resveratrol se concentra na casca, o tempo de maceração durante o processo de fermentação do mosto constitui fator determinante na sua extração ${ }^{33}$. Outros processos como, a adição de agentes clarificantes e a filtração, podem reduzir o conteúdo de resveratrol no produto final ${ }^{34,37}$.

Estes resultados sugerem que a variação no perfil dos compostos fenólicos pode resultar em diferentes respostas biológicas, e apesar das antocianinas e do resveratrol representarem os constituintes potenciais, outros compostos podem estar agindo sinergisticamente, contribuindo para os efeitos benéficos associados ao consumo de uvas e seus derivados.

As uvas das espécies de Vitis labrusca são denominadas uvas rústicas ou comuns. De maneira geral, estas videiras caracterizam-se por apresentarem elevada produtividade e alta resistência às doenças que normalmente atacam as cultivares de Vitis vinifera, conhecidas como uvas finas. No Brasil, até poucos anos atrás, as variedades de uvas da espécie Vitis vinifera tinham seu cultivo praticamente limitado aos Estados mais frios do país, como Rio Grande do Sul e Santa Catarina, porém as técnicas de enxertia originaram plantas mais resistentes, com maior vigor e melhor adaptação aos diferentes tipos de solo, possibilitando seu cultivo em outras regiões. Assim, regiões brasileiras de clima quente como Minas Gerais, onde é mais comum o cultivo de Vitis labrusca, rústica e resistente, podem também produzir uvas finas ${ }^{23}$.

Os resultados mais relevantes dentre as cultivares avaliadas foram em relação às diferenças na porcentagem de antocianinas e flavanóis (catequinas e epicatequinas). Nas cultivares Folha de figo, Syrah e Merlot, as antocianinas representam entre 70 e $80 \%$ do total de flavonóides. A cultivar Niágara rosada, de coloração menos intensa, apresentou menor conteúdo de antocianinas em comparação com outras cultivares coloridas. Nesta cultivar, as catequinas e epicatequinas representam cerca de 80 a $90 \%$ do total de flavonóides. A cultivar Moscato Embrapa, de bagas brancas, foi a que se destacou por apresentar menor quantidade de fenólicos totais. Não obstante, a ausência de antocianinas também não apresentou nenhum outro composto em quantidades relevantes. O conteúdo de fenólicos totais na uva branca foi aproximadamente 5 vezes menor que a média obtida para outras cultivares. Isto, aliado ao fato da fermentação dos mostos brancos ocorrer na ausência de cascas e sementes, contribui para a presença de quantidades inferiores de compostos fenólicos em vinhos brancos quando comparados com vinhos tintos ${ }^{3}$.

De acordo com estas observações, presume-se que o perfil de compostos fenólicos nas cultivares avaliadas não depende necessariamente da espécie, sendo mais variável de acordo com a cultivar, já que compostos como o resveratrol e caempferol podem ou não estar presentes tanto em cultivares de Vitis vinifera quanto de Vitis labrusca. O conteúdo de antocianinas certamente varia de acordo com a coloração da uva, pois as cultivares de uvas mais escuras apresentaram os maiores teores de antocianinas, seguidas pelas uvas rosadas e sendo ausentes em uvas brancas, como era de se esperar.

Em relação à influência do porta-enxerto no teor de compostos fenólicos, observou-se diferença significativa no teor de antocianinas e na capacidade antioxidante para a cultivar Folha de figo, com valores superiores para o porta-enxerto 420A (Tabela 3). O maior teor de antocianinas foi compensado pelo menor conteúdo de flavanóis em relação ao porta-enxerto 196-17, não havendo diferença significativa entre os teores de fenólicos totais e flavonóides totais (Tabelas 2 e 3 ).

\section{Conclusões}

As uvas da cultivar Folha de figo sobre o porta-enxerto 420A apresentaram maior conteúdo de fenólicos totais, antocianinas totais e capacidade antioxidante, enquanto as uvas da cultivar Moscato Embrapa, livres de antocianinas, apresentaram teores de fenólicos totais e capacidade antioxidante significativamente inferiores.

As cultivares de uvas analisadas apresentaram forte correlação entre o conteúdo de antocianinas totais e capacidade antioxidante. 
Tabela 3. Conteúdo de fenólicos totais (mg. $100 \mathrm{~g}^{-1}$ equivalentes de ácido gálico), antocianinas totais (mg. $100 \mathrm{~g}^{-1}$ equivalentes de cianidina3 -glicosídeo) e capacidade antioxidante ( $\mu$ mol equivalente de Trolox.g ${ }^{-1}$ amostra) de cultivares de videiras produzidas em Minas Gerais na safra 2005/2006.

\begin{tabular}{lccc}
\hline \multicolumn{1}{c}{ Cultivar } & $\begin{array}{c}\text { Fenólicos } \\
\text { totais }\end{array}$ & $\begin{array}{c}\text { Antocianinas } \\
\text { totais }\end{array}$ & $\begin{array}{c}\text { Capacidade } \\
\text { antioxidante }\end{array}$ \\
\hline Niágara rosada IAC 766 & $208 \pm 12^{\mathrm{c}}$ & $12,8 \pm 0,1^{\mathrm{d}}$ & $7,6 \pm 0,4^{\mathrm{e}}$ \\
Niágara rosada 196-17 & $214 \pm 13^{\mathrm{c}}$ & $18 \pm 2^{\mathrm{d}}$ & $7,6 \pm 0,5^{\mathrm{e}}$ \\
Folha de figo 420A & $391 \pm 30^{\mathrm{a}}$ & $248 \pm 24^{\mathrm{a}}$ & $19 \pm 2^{\mathrm{a}}$ \\
Folha de figo 196-17 & $390 \pm 28^{\mathrm{a}}$ & $198 \pm 16^{\mathrm{b}}$ & $13,8 \pm 0,9^{\mathrm{b}}$ \\
Syrah & $385 \pm 30^{\mathrm{a}}$ & $111,8 \pm 0,2^{\mathrm{c}}$ & $10,3 \pm 0,3^{\mathrm{d}}$ \\
Merlot & $337 \pm 21^{\mathrm{b}}$ & $97 \pm 7^{\mathrm{c}}$ & $12,1 \pm 0,6^{\mathrm{c}}$ \\
Moscato Embrapa & $65 \pm 1^{\mathrm{d}}$ & n.d. & $2,7 \pm 0,1^{\mathrm{f}}$ \\
\hline
\end{tabular}

Os resultados estão expressos na forma de média \pm desvio padrão $(n=3)$. Médias com letras diferentes na mesma coluna são significativamente diferentes $(\mathrm{p}<0,05)$.

Quanto mais intensa a coloração da uva, mais interessante se torna do ponto de vista funcional, já que as uvas de coloração escura apresentaram maior conteúdo de compostos fenólicos e capacidade antioxidante.

\section{Agradecimentos}

Ao Núcleo Tecnológico EPAMIG Uva e Vinho, pelo fornecimento das amostras. Ao CNPq, pelo apoio financeiro e à CAPES, pela bolsa concedida.

\section{Referências bibliográficas}

1. AlVAREnGA, A. A. et al. Influência do Porta-enxerto sobre o Crescimento e Produção da Cultivar de Videira Niágara Rosada (Vitis labrusca x Vitis vinifera L.) em Condições de Solo Acido. Ciênc. Agrotecnol., Lavras, v. 26, n. Especial, p. 1459-1464, 2002.

2. ARABBI, P. R.; GENOVESE, M. I.; LAJOLO, F. M. Flavonoids in vegetable commonly consumed in Brazil and estimated ingestion by the Brazilian population. J. Agric. Food Chem., v. 52, p. 1124-1131, 2004.

3. BEER, D. et al. Antioxidant activity of South African red and white cultivar wines: Free radical scavenging. J. Agric. Food Chem., v. 51, p. 902-909, 2003.

4. BURNS, J. et al. Plant foods -and herbal sources of resveratrol. J. Agric. Food Chem., v. 50, p. 3337-3340, 2002.

5. CABRITA, M. J.; RICARDO-DA-SILVA, J.; LAUREANO, O. Os compostos polifenólicos das uvas e dos vinhos. In: I SEMINÁRIO INTERNACIONAL DE VITIVINICULTURA. Anais...Ensenada, México, 2003.

6. CANTOS, E.; ESPÍN, J. C.; TOMÁS-BARBERÁN, F. A. Varietal diferences among the polyphenol profiles of seven table grape cultivars studied by LC-DAD-MS-MS. J. Agric. Food Chem., v. 50, p. 5691-5696, 2002.

7. CHAMPAGnOL, F. Elements de Physiologie de la Vigne et de Viticulture Generale. Saint-Gely-du-Fesc: Champagnol. 1984. $351 \mathrm{p}$.

8. COUNET, C.; CALLEMIEN, D.; COLLIN, S. Chocolate and cocoa: New sources of trans-resveratrol and trans-piceid. Food Chem., v. 98, p. 649-657, 2006.

9. DELMAS, D.; JANNIN, B.; LATRUFFE, N. Resveratrol: Preventing properties against vascular alterations and ageing. Mol. Nutr. Food Res., v. 49, p. 377-395, 2005.
10. DUARTE AlMEIDA, J. M. et al. Avaliação da atividade antioxidante utilizando sistema $\beta$-caroteno/ácido linoléico e método de seqüestro de radicais DPPH. Ciênc. Tecnol. Aliment. v. 26, n. 2, p. 446-452, 2006.

11. FAN, E. et al. Determination of trans-resveratrol in China Great Wall "Fazenda" Red Wine by use of micellar electrokinetic chromatography. Chromatographia, v. 62, p. 289-294, 2005.

12. FARIA, A. et al. Procyanidins as antioxidants and tumor cell growth modulators. J. Agric. Food Chem., v. 54, p. 2392-2397, 2006.

13. GONÇALVES, C. A. A. et al. Fenologia e Qualidade do mosto de Videiras 'Folha de Figo' Sobre Diferentes Porta-enxertos, em Caldas, Sul de Minas Gerais. Ciênc. Agrotecnol., Lavras, v. 26, n. 6, p. 1178-1184, 2002.

14. GUSMAN, J.; MALONNE, H.; ATASSI, G. A repraisal of the potential chemopreventive and chemotherapeutic properties of resveratrol. Carcinogenesis, v. 22, n. 8, p. 1111-1117, 2001.

15. HASSimoto, N. M. A.; GenOVESE, M. I.; LAJOLO, F. M. Antioxidant activity of dietary fruits, vegetables, and commercial frozen fruit pulps. J. Agric. Food Chem., v. 53, p. 2928-2935, 2005.

16. HAYEK, T. et al. Reduced Progression of Atherosclerosis in Apolipoprotein E-Deficient Mice Following Consumption of Red Wine, or Its Polyphenols Quercetin or Catechin, Is Associated With Reduced Susceptibility of LDL to Oxidation and Aggregation. Arterioscler. Thromb. Vasc. Biol., v. 17, p. 2744-2752, 1997.

17. HOLLMAN, P. C. H. Evidence for health benefits of plant phenols: local or systemic effects? J. Sci. Food Agric., v. 81, p. 842-852, 2001.

18. INSTITUTO ADOLFO LUTZ. Normas Analíticas do Instituto Adolfo Lutz. Métodos químicos e físicos para análise de alimentos, v. 1, 3. ed. São Paulo: Inst. Adolfo Lutz, 1985. $533 \mathrm{p}$.

19. KALLITHRAKA, S. et al. Determination of major anthocyanin pigments in Hellenic native grape varieties (Vitis vinifera $\mathrm{sp.)}$ : association with antiradical activity. J. Food Comp. Anal., v. 18, p. 375-386, 2005.

20. KAMMERER, D. et al. Polyphenol screening of pomace from red and white grape varieties (Vitis vinifera $\mathrm{L}$.) by HPLC-DAD-MS/MS. J. Agric. Food Chem., v.52, p. 4360-4367, 2004.

21. LAMUELA-RAVENTÓS, R. M. et al. Direct HPLC analysis of cis and trans-resveratrol and piceid isomers in Spanish red Vitis vinifera wines. J. Agric. Food Chem., v. 43, p. 281-283, 1995.

22. LANGCAKE, P.; PRYCE, R. J. The production of resveratrol by Vitis vinifera and other members of the Vitaceae as a response to infection or injury. Physiol. Plant Pathol., v. 9, p. 77-86, 1976.

23. MAIA, J. D. G.; CAMARGO, U. A. Sistema de Produção de Uvas Rústicas para Processamento em Regiões Tropicais do Brasil. Embrapa Uva e Vinho, 2005. Disponível em: http://sistemasdeproducao.cnptia.embrapa.br/FontesHTML/ Uva/UvasRusticasParaProcessamento/cultivares. Acesso em: 10 jul. 2006.

24. MAXCHEIX, J. J.; FLEURIET, A.; BILLOT, J. The main phenolics of fruits. In Fruit Phenolics; CRC Press: Boca Raton, FL, 1990; p. 1-98.

25. MEYER, A. S. et al. Inhibition of human low-density lipoprotein oxidation in relation to composition of phenolics antioxidants in grapes (Vitis vinifera). J. Agric. Food Chem., v. 45, p. 1638-1643, 1997. 
26. MITJANS, M. et al. Immunomodulatory activity of a new family of antioxidants obtained from grape polyphenols. J. Agric. Food Chem., v. 52, p. 7297-7299, 2004.

27. MORENO-LABANDA, J. F. et al. Determination of piceid and resveratrol in spanish winws deriving from Monastrell (Vitis vinifera L.) grape variety. J. Agric. Food Chem., v. 52, p. 5396-5403, 2004.

28. MUÑOZ-ESPADA, A. C. et al. Anthocyanin quantification and radical scavening capacity of Concord, Norton, and Marechal Foch Grapes and wines. J. Agric. Food Chem., v. 52, p. 6779-6786, 2004.

29. ORDAZ-GALINDO, A. et al. Purification and identification of Capulin (Prunus serotina Ehrh) anthocyanins. Food Chem., Oxford, v. 65, n. 2, p. 201-206, 1999.

30. PIRES, E. J. P.; POMMER, C. V. Fisiologia da Videira. In: POMMER, C. V. (ed.) UVA - Tecnologia de Produção, Pós-colheita, Mercado. Porto Alegre: Cinco Continentes, 2003. Cap. 4, p. 250-294.

31. POMAR, F.; NOVO, M.; MASA, A. Varietal differences among the anthocyanin profile of 50 red table grape cultivars studied by hight performance liquid chromatography. J. Chromatogr. A, v. 1094, p. 34-41, 2005.

32. REGINA, M. A. et al. Comportamento da cultivar Folha de Figo (Vitis labrusca L.) sobre diferentes porta-enxertos de Videira. Rev. Bras. Fruticult., Jaboticabal, v. 21, n. 1, p. 7-11, 1999.
33. RIMANDO, A. G. et al. Resveratrol, pterostilbene, and piceatannol in Vaccinium berries. J. Agric. Food Chem., v. 52, p. 4713-4719, 2004.

34. ROMERO-PÉREZ, A. I. et al. Piceid, the major resveratrol derivative in grape juices. J. Agric. Food Chem., v. 47, p. 1533-1536, 2004.

35. SAUTTER, C. K. et al. Determinação de resveratrol em sucos de uva no Brasil. Ciênc. Tecnol. Aliment., v. 25, n. 3, p. 437-442, 2005.

36. STINTZING, F. C. et al. Color and antioxidant properties of cyanidin-based anthocyanin pigments. J. Agric. Food Chem. v. 50, p. 6172-6181, 2002.

37. THRELFALL, R. T.; MORRIS, J. R.; MAUROMOUSTAKOS, A. Effect of variety, ultraviolet light exposure, and enological methods on the trans-resveratrol level of wine. Am. J. Enol. Vitic., v. 50, n. 1, p. 57-64, 1999.

38. WROLSTAD, R. E. Color and pigment analysis in fruit products Corvallis: Oregon Agricultural Experimental Station, 1976, $17 \mathrm{p}$.

39. YILMAZ, Y.; TOLEDO, R. T. Major flavonoids in grape seeds and skins: Antioxidant capacity of catechin, epicatechin, and gallic acid. J. Agric. Food Chem., v. 52, p. 255-260, 2004.

40. ZIELINSKI, H.; KOZLOWSKA, H. Antioxidant activity and total phenolics in selected cereal grains and their different morphological fractions. J. Agric. Food Chem., v. 48, p. 2008-2016, 2000. 